\title{
Oxidative Degradation of Cellulose Derivatives In Aqueous Solution of Chromic Acid
}

\author{
Tatsuo Sato and David A. Katila \\ Metal Coatings Division, Diamond Shamrock Corporation, \\ P. O. Box 127, 5th Avenue, Chardon, Ohio 44024, U.S.A.
}

(Received November 17, 1977)

\begin{abstract}
Degradation of cellulose derivatives (hydroxyethyl ether and hydroxypropylmethyl ether) in water in the presence of chromic acid was investigated viscometrically. The degradation was followed by determination of the change in the apparent viscosity of the solution with a Brookfield viscometer and the change in the intrinsic viscosity with an Ubbelohde viscometer. It was found that the viscosity decreased with time and the rate of viscosity reduction decreased with the decrease in the molecular weight. It was confirmed by the determination of the change in the intrinsic viscosity that the decrease in the apparent viscosity was due to the random degradation of the polymers. A linear relationship was found between the change in the reciprocal of molecular weight of polymers and the change in the concentration of hexavalent chrome in the solution, which indicates that the degradation proceeds via a random oxidative-degradation process.
\end{abstract}

KEY WORDS Random Degradation / Hydroxyethyl Ether / Hydroxypropylmethyl Ether / Intrinsic Viscosity / Flow Index / Chromic Acid / Oxidative Degradation /

Mechanical degradation of the cellulose derivatives in water by ultrasonic irradiation was investigated previously by one of the authors ${ }^{1,2}$ and the relationship between the number-average molecular weight $\left(\bar{M}_{n}\right)$ and the irradiation time $(t)$ was found to obey eq 1 .

$$
\begin{aligned}
\frac{1}{\bar{M}_{n, t}} & =\frac{1}{\bar{M}_{n, 0}}+k^{\prime} t \\
k^{\prime} & =k / \bar{M}_{0}
\end{aligned}
$$

where $\bar{M}_{n, t}$ and $\bar{M}_{n, 0}$ are the molecular weight of polymer at $t=t$ and $t=0$, respectively, $\vec{M}_{0}$, the average molecular weight of each monomer unit, and $k$ the rate constant.

In the present work, the applicability of this equation to the chemical degradation of the cellulose derivatives in the presence of chromic acid was examined in order to compare the chemical mode of the degradation to the mechanical one.

\section{EXPERIMENTAL}

\section{Materials}

Cellulose derivatives used in this work were commercial hydroxyethyl cellulose (HEC) and hydroxypropylmethyl cellulose (HPMC) supplied by Union Carbide Corporation and Dow Chemical Company, respectively. Their properties are given in Table $\mathrm{I}$.

\section{Procedure}

Cellulose derivatives and chromic acid were dissolved in deionized water separately and mixed after they were dissolved. The measurement of the change in parameters of the solutions with time was started after mixing the polymer solutions and the chromic acid solutions. The solutions were stored at $20^{\circ} \mathrm{C}$ in the dark since the cellulose derivatives are very sensitive to photolysis in the presence of chromic acid. ${ }^{3}$ The apparent viscosity was measured by a Brookfield viscometer (LVT type) with various shear rates at $20^{\circ} \mathrm{C}$. The intrinsic viscosity $[\eta]$ was measured with an Ubbelohde viscometer $20^{\circ} \mathrm{C}$ and $25^{\circ} \mathrm{C}$. The number-average molecular weight of the polymers was calculated by the following equations.

For $\mathrm{HEC}^{4}$ :

$$
[\eta]_{25^{\circ} \mathrm{C}}=4.70 \times 10^{-4} \bar{M}_{n}{ }^{0.80}
$$


Table 1. Property of cellulose derivatives

\begin{tabular}{|c|c|c|c|}
\hline $\begin{array}{l}\text { Cellulose } \\
\text { derivative }\end{array}$ & $\begin{array}{l}\text { HPMC } \\
(\mathrm{K}-35)\end{array}$ & $\begin{array}{l}\text { HPMC } \\
(\mathrm{F}-4 \mathrm{M})\end{array}$ & HEC \\
\hline Trade name & $\begin{array}{l}\text { Methocel }{ }^{\circledR} \\
\text { K-35 }\end{array}$ & $\begin{array}{l}\text { Methocel } \\
\text { F-4M }\end{array}$ & $\begin{array}{l}\text { Cellosize }{ }^{\circledR} \\
\text { QP-4400 }\end{array}$ \\
\hline $\begin{array}{l}\text { Manufac- } \\
\text { turer }\end{array}$ & $\begin{array}{l}\text { Dow } \\
\text { Chemical } \\
\text { Co. }\end{array}$ & $\begin{array}{l}\text { Dow } \\
\text { Chemical } \\
\text { Co. }\end{array}$ & $\begin{array}{l}\text { Union } \\
\text { Carbide } \\
\text { Corp. }\end{array}$ \\
\hline $\begin{array}{l}\text { Chemical } \\
\text { structure }\end{array}$ & $\begin{array}{l}\text { Hydroxy- } \\
\text { propyl- } \\
\text { methyl } \\
\text { cellulose }\end{array}$ & $\begin{array}{l}\text { Hydroxy- } \\
\text { propyl- } \\
\text { methyl } \\
\text { cellulose }\end{array}$ & $\begin{array}{l}\text { Hydroxy- } \\
\text { ethyl } \\
\text { cellulose }\end{array}$ \\
\hline $\begin{array}{l}\text { Molar } \\
\text { substitu- } \\
\text { tion }^{\mathrm{a}}\end{array}$ & $0.1-0.3$ & $0.1-0.2$ & 1.67 \\
\hline $\begin{array}{l}\text { Degree of } \\
\text { substitu- } \\
\text { tion }^{b}\end{array}$ & $1.1-1.6$ & $1.7-1.9$ & 0.88 \\
\hline$[\eta]_{20^{\circ} \mathrm{C}}, \mathrm{d} l / \mathrm{g}$ & 2.1 & 5.5 & 8.5 \\
\hline$[\eta]_{25^{\circ} \mathrm{C}}, \mathrm{d} l / \mathrm{g}$ & - & - & 8.2 \\
\hline $\bar{M}_{n}$ & $20.4 \times 10^{3}$ & $57.5 \times 10^{3}$ & $182.0 \times 10^{3}$ \\
\hline
\end{tabular}

a The average number of ethylene oxide molecules per anhydroglucose unit.

b The average number of hydroxyls substituted per anhydroglucose unit.

and for $\mathrm{HPMC}^{5}$ :

$$
[\eta]_{20^{\circ} \mathrm{C}}=3.39 \times 10^{-4} \bar{M}_{n}^{0.88}
$$

Although the above equations were obtained for pure water-polymer systems, it has been confirmed that the intrinsic viscosity for the cellulose derivatives was not affected by the presence of chromic

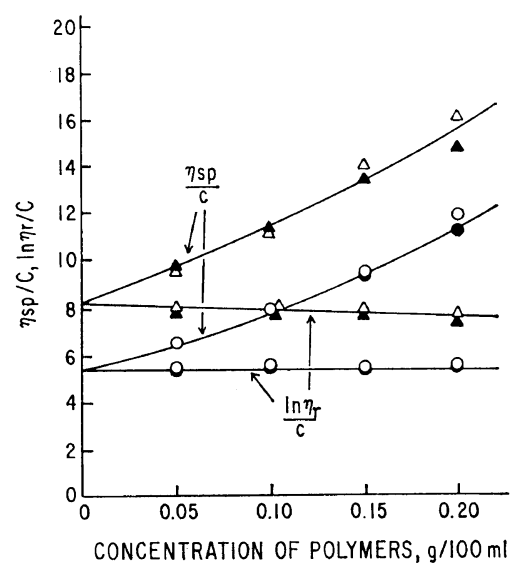

Figure 1. $\eta_{\mathrm{sp}} / C$ and $\ln \eta_{\mathrm{r}} / C$ vs. concentration of polymers, at $20^{\circ} \mathrm{C}: \triangle$, HEC $\left(\mathrm{CrO}_{3}=0 \%\right) ; \Delta, \mathrm{HEC}$ $\left(\mathrm{CrO}_{2}=0.4 \%\right) ; \mathrm{O}, \mathrm{F}-4 \mathrm{M} \quad\left(\mathrm{CrO}_{3}=0 \%\right) ; \bullet, \mathrm{F}-4 \mathrm{M}$ $\left(\mathrm{CrO}_{3}=0.4 \%\right)$. acid in the concentration range used in this work, as shown in Figure 1. Hence, eq 2 and 3 are valid for chromic acid solutions as well as for water.

The change in the hexavalent chrome concentration, $[\mathrm{Cr}(\mathrm{VI})]$, with time in the solution was determined by the iodometric titration.

\section{RESULTS AND DISCUSSION}

\section{Change in the Apparent Viscosity with Time}

The change in the Brookfield viscosity (spindles, No. 1 and 2; shear rate, $30 \mathrm{rpm}$; the mean shear rate, $5.5 \mathrm{sec}^{-1}$ ) of aqueous chromic acid solution $\left(\mathrm{CrO}_{3}, 0.4 \mathrm{wt} \%\right)$ of the cellulose derivatives with time is shown in Figure 2. The initial viscosity of all solutions was adjusted to about $210 \mathrm{cps}$ by varying the concentration of polymers over a range $1-4 \%$. The figure shows that the rate of viscosity reduction increases with the increase in the molecular weight of polymers. This result is in close agreement with that of mechanical degradation. The increase in the degradation rate with molecular weight is probably due to the increase in the probability of a chain break occurring with the increase in the chain length.

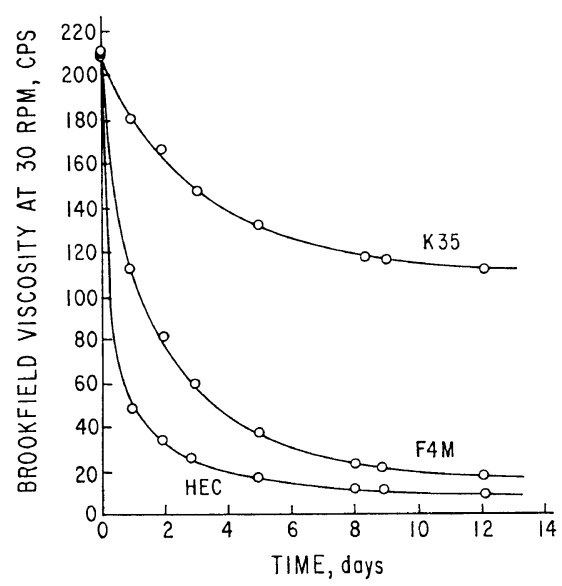

Figure 2. Change in viscosity of polymer solutions containing $0.4-\% \mathrm{CrO}_{3}$ with aging time.

Change in the Intrinsic Viscosity and Concentration of Hexavalent Chrome

The change in the intrinsic viscosity with time was measured to determine the change in molecular weight of polymer with degradation. Figure 3 shows that HEC degrades faster than HPMC F4M. The Huggins constant $k^{\prime}$ for polymers 


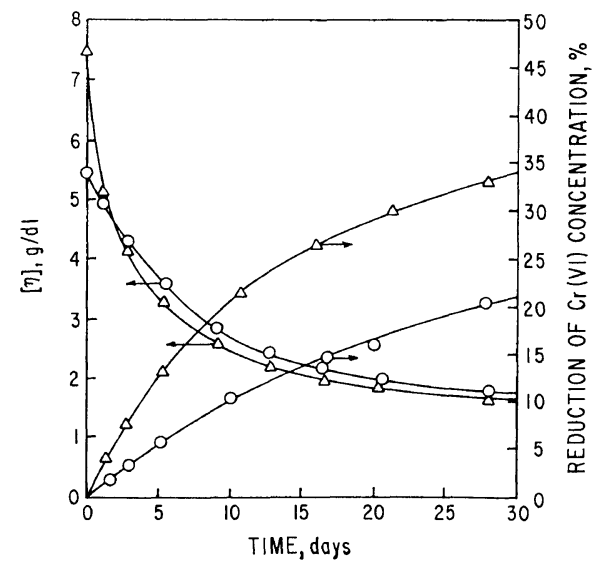

Figure 3. Change in the intrinsic viscosity and hexavalent chrome concentration with time: $O, F-4 M$; $\triangle$, HEC.

tends to decrease with degradation, although it was constant in the case of mechanical degradation. The decrease in the Huggins constant is probably due to the increase in the polymersolvent affinity caused by the increase in the carbonyl group, as observed in the infrared spectra.

The change in the concentration of hexavalent chrome $\mathrm{Cr}(\mathrm{VI})$ was measured by iodometric titration. The concentration of $\mathrm{Cr}(\mathrm{VI})$ decreases with time since hexavalent chrome is consumed as the oxidation of polymer progresses. Figure 3 shows that the reduction of $\mathrm{Cr}(\mathrm{VI})$ increases with time and that the rate of reduction decreases with time.

\section{Change in the Molecular Weight with Time}

The changes in molecular weight, $\bar{M}_{n}$, and the reciprocal of molecular weight, $1 / \bar{M}_{n}$ of the polymers with aging time, $t$, are shown in Figure 4. Although a linear relationship was observed between $1 / \bar{M}_{n}$ and $t$ in the case of mechanical degradation, ${ }^{2}$ it was not observed in this case. In this system, the rate of degradation decreases with time since the hexavalent chrome concentration decreases with time. Figure 5 shows that there is a linear relationship between the reciprocal of molecular weight and the hexavalent chrome concentration. This result is in close agreement with the results of McBurney. ${ }^{6,7}$ The linear relationship in the figure indicates that the degradation of cellulose derivatives with chromic acid is the random degradation due to the oxidation.

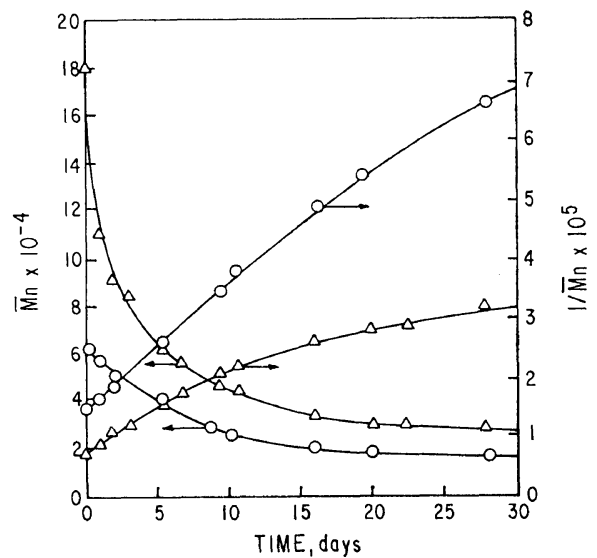

Figure 4. Change in molecular weight and the reciprocal of molecular weight of polymer with time: $\mathrm{O}, \mathrm{F}-4 \mathrm{M} ; \triangle$, HEC.

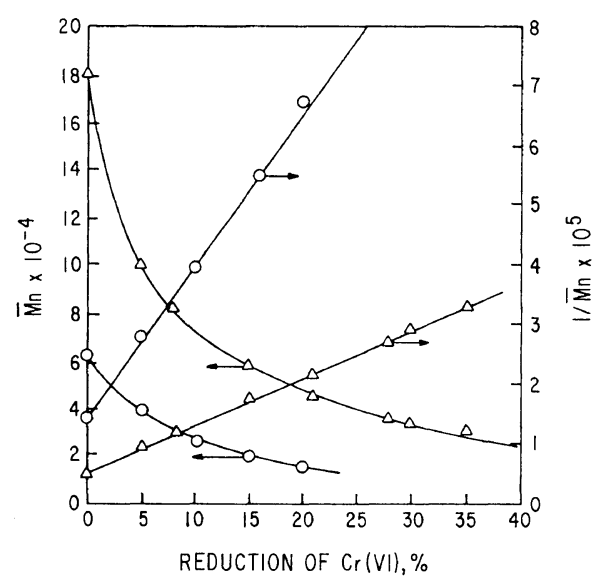

Figure 5. Change in molecular weight and the reciprocal of molecular weight of polymers with change in the hexavalent chrome concentration: $O, F-4 M$; $\triangle$, HEC.

\section{FTIR Study on the Structure of Cellulose Derivatives}

The change in the molecular structure with the degradation was investigated by infrared spectroscopy. Infrared spectra of chromic acid/polymer mixtures were obtained by evaporating the aqueous solutions on KRS plates. A strong peak was observed at $1725 \mathrm{~cm}^{-1}$ in the mixture of polymer/ chromic acid, which was not observed either in polymer or in chromic acid. The peak at 1725 $\mathrm{cm}^{-1}$ is due to the presence of carbonyl $(\mathrm{C}=\mathrm{O})$ group in the material. The presence of this peak and the distortion of the $\mathrm{OH}$ stretch vibrational 
mode in the $3000 \mathrm{~cm}^{-1}$ region indicates that the cellulose derivatives were significantly oxidized and partially converted to a carboxylic acid. This type of degradation is generally observed in the reaction of cellulosic materials with other oxidizing reagents. ${ }^{8}$

\section{Change in Rheological Property by Degradation}

Figure 6 shows the logarithmic shear stress $(\tau)$-shear rate $(\dot{\gamma})$ plots for the cellulose derivative chromic acid solutions which were not aged or aged for 14 days. The relationship between $\tau$ and $\dot{\gamma}$ is expressed by the power law ${ }^{1}$

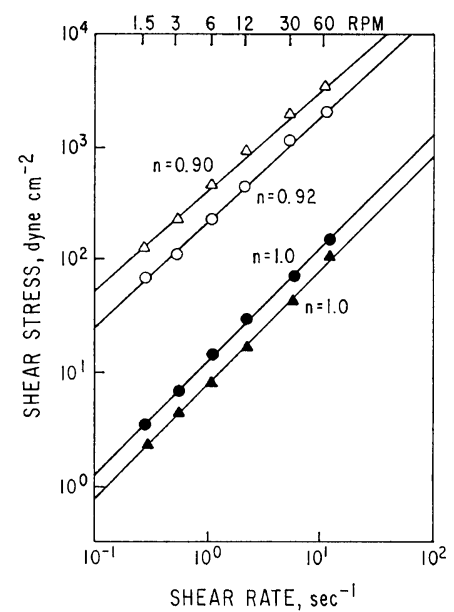

Figure 6. Shear stress $v s$. shear rate for aged and not aged polymer solutions containing $0.4-\% \mathrm{CrO}_{3}$, at $20^{\circ} \mathrm{C}$ : $\mathrm{O}, \mathrm{F}-4 \mathrm{M}$ (not aged);, $\mathrm{F}-4 \mathrm{M}$ (aged for 14 days); $\triangle$, HEC (not aged); $\triangle$, HEC (aged for 14 days).

$$
\log \tau=\log K+n \log \dot{\gamma}
$$

where $K$ is the consistency index and $n$ is the "flow index," which is a measure of the degree of deviation from Newtonian behavior. If $n=1$, the solution is Newtonian, $n$ and $K$ being obtained from the slope of the lines and the intercept of the lines at $\log \dot{\gamma}=0$, respectively. Figure 6 shows that $n$ approaches unity with aging time, indicating that the solutions become Newtonian with degradation, which agrees with the mechanical degradation. $^{1}$

Acknowledgements. The authors wish to acknowledge Drs. L. Bourland and S. Lowry of the Research Center of Diamond Shamrock Corporation for useful discussions.

\section{REFERENCES}

1. T. Sato and D. E. Nalepa, J. Coat. Technol., 49 (No. 629), 45 (1977).

2. T. Sato and D. E. Nalepa, J. Appl. Polym. Soi., 22, 865 (1978)

3. T. Sato, unpublished result.

4. R. St. J. Manley, Arkiv Kemi, 9, 519 (1956).

5. "Handbook on Methocel," 6-3, Dow Chemical Company.

6. L. F. McBurney, Ind. Eng. Chem., 41, 1251 (1949).

7. E. F. Evans and L. F. McBurney, ibid., 41, 1260 (1949).

8. E. Ott, H. M. Spurlin, and M. W. Graffin, "Cellulose and Cellulose Derivatives," Part I, Interscience Publisher, New York, N. Y., 1954, p 144. 